\title{
El extranjero de Albert Camus traducido por Pablo Montoya: ¿Una traducción PARA LECTORES LATINOAMERICANOS?
}

\author{
L'étranger, d'Albert Camus traduit par Pablo Montoya : une traduction \\ POUR DES LECTEURS LATINO-AMÉRICAINS ?
}

\author{
Albert Camus' The Stranger, Translated by Pablo Montoya: A Translation \\ FOr LATIN AMERICAN READERS?
}

\author{
Élodie Weber \\ Doctora en Lingüística Hispánica, \\ Université Paris-Sorbonne, Francia. \\ Profesora titular, Departamento de \\ Estudios Ibéricos y Latinoamericanos, \\ Université Paris-Sorbonne, París, \\ Francia. \\ el.web@free.fr
}

\begin{abstract}
RESUMEN
El presente estudio se inscribe en una investigación sobre la traducción literaria hoy en día en Colombia desde un punto de vista lingüístico y más particularmente léxico. Las traducciones de obras de la literatura universal en español peninsular que comenzaron a circular en América Latina a partir de los años sesenta generaban entre los lectores una sensación de extrañeza que puede atribuirse a ciertas variaciones diatópicas. Esto motivó varias iniciativas editoriales de retraducción de esas obras por traductores latinoamericanos. A fin de contrastar la diferencia entre las versiones peninsulares y las realizadas en Colombia, este artículo examina el caso de dos traducciones de la obra del escritor francés Albert Camus L'étranger (1942), una del docente y escritor colombiano Pablo Montoya, publicada en 2013, y la otra del poeta español José Ángel-Valente, aparecida en 2001. La comparación entre estas traducciones permite identificar diferencias, tanto morfosintácticas como lexicales, las cuales se intentan caracterizar desde un punto de vista diatópico, gracias a estudios especializados, al motor de búsqueda CREA de la Real Academia y a una encuesta a informantes. Se concluye que la traducción de Montoya, aunque dirigida a un público colombiano, lleva pocas marcas diatópicas específicamente colombianas y, al contrario, se inscribe en el espacio y la cultura latinoamericanos, por lo que podría ser leída sin extrañeza por otros lectores de la región.
\end{abstract}

Palabras claves: traducción literaria; recepción; traducción en Colombia; traductores latinoamericanos; Albert Camus; variaciones diatópicas.

\section{RÉSUMÉ}

Cette étude s'inscrit dans le cadre d'une recherche sur l'état actuel de la traduction littéraire en Colombie d'un point de vue linguistique, et plus particulièrement lexical. Les traductions en espagnol péninsulaire des oeuvres de la littérature universelle qui ont commencé à circuler en Amérique Latine dès années 60 ont causés des sentiments d'étrangeté dans les lecteurs latino-américains, qu'on peut attribuer a des variations diatopiques. Ça a motivé des projets éditoriaux de re-traduction de ces oeuvres par des traducteurs latino-américains. Afin de comparer les traductions péninsulaires avec celles réalisées en Colombie, cet article se propose d'examiner le cas de deux

Recibido: 2019-06-05 / Aceptado: 2019-11-15 / Publicado: 2020-05-05

https://doi.org/10.17533/udea.ikala.v25n02a12 
traductions de L'étranger (1942) de Camus, l'une par l'écrivain et professeur d'université colombien Pablo Montoya, publiée en 2013, l'autre par le poète espagnol José Ángel-Valente, apparue en 2001. La comparaison de ces traductions permet de mettre au jour des différences morphosyntaxiques et lexicales que l'on tente de caractériser d'un point de vue diatopique, grâce à des ouvrages spécialisés, au moteur de recherche CREA et à une enquête auprès d'informateurs hispanophones. L'on parvient à la conclusion que la traduction de Montoya, bien qu'adressée à un public colombien, comporte peu de marques diatopiques spécifiquement colombiennes et s'ancre au contraire dans la culture et l'espace latino-américains, de sorte qu'elle pourrait être lue par d'autres lecteurs latino-américains.

Mots clés : traduction littéraire; réception ; traduction en Amérique-latine ; traducteurs latino-américains; Albert Camus ; variations diatopiques.

\section{Abstract}

This study is part of a research project on the current state of literary translation in Colombia from a linguistic and, more specifically, a lexical point of view. Universal literature works translated to peninsular Spanish that began to circulate across Latin America in the 60s oftentimes left some perception of unnaturalness in readers, which can be attributed to some diatopic variations. This led to a number of editorial efforts to have those works retranslated by Latin American translators. In order to contrast peninsular translations with those carried out in Colombia, this paper examines the case of two translations of L'étranger (1942) by French writer Camus - one by Colombian writer and lecturer Pablo Montoya, published in 2013, the other by the Spanish poet José Ángel-Valente, which appeared in 2001. The comparison between these translations allows us to show both morphosyntactic and lexical differences, which we tried to characterize from a diatopic point of view through specialized books, through the CREA search engine and through a survey of Spanish-speaking informants. The analysis showed that Montoya's translation, although addressed to a Colombian audience, contains few specifically Colombian diatopic marks and is rooted instead in Latin American space and culture, so it could be easily read by other American readers.

Keywords: literary translation; reception; translation in Latin America; Latin American translators; Albert Camus; diatopic variations. 


\section{Introducción}

La situación de la traducción literaria en el mundo hispanohablante cambió radicalmente en la segunda mitad del siglo xx. Hasta los años 60, se traducían libros de forma independiente a ambos lados del Atlántico, de tal modo que a menudo existían varias traducciones de una misma obra realizadas sin ninguna concertación en España y en América Latina. En esa década, las editoriales españolas empezaron a interesarse por el continente latinoamericano, que veían como un posible mercado de exportación para sus obras extranjeras traducidas (Gómez-Pablos, 1999, p. 135). En esa época se abrieron firmas en distintos países latinoamericanos, que inicialmente se encargaron de la distribución de esas obras, y luego de la impresión, con el fin de reducir gastos de producción y transporte. En un primer momento, el editor español no se planteó la disyuntiva de usar o no las variantes locales de la lengua. Como señalaba Gómez-Pablos, "Su punto de partida es el castellano que considera estándar, es decir, el de la Península Ibérica" (1999, p. 135).

$\mathrm{Al}$ leer estas traducciones que circulaban en América Latina, los lectores latinoamericanos experimentaban, y siguen experimentando, una fuerte insatisfacción: muchas veces el uso de la lengua se percibía como ajeno y hasta molesto. Fue así como, en los años 90, se discutió en Argentina la necesidad de revisar las traducciones hechas en España; tal fue la propuesta del narrador y ensayista argentino Eduardo Gudiño Kieffer, citado por la lingüista Fontanella de Weinberg: "las editoriales locales deberían tener en cuenta algo que otras de Buenos Aires ya hacen: cuando un libro viene traducido de España, conviene que la traducción sea revisada aquí" (1992, pp. 72-73).

El mismo sentimiento de insatisfacción se manifestaba en México, tal como lo comenta el editorialista francés Pierre Assouline:

De hecho, actualmente hay editores, escritores, traductores y críticos en los círculos literarios mexicanos que creen que los libros extranjeros traducidos al español deben ser traducidos al "idioma" de los países latinoamericanos a los que se dirigen, y no al castellano puro, al que se culpa de ignorar los americanismos (2009, mi traducción).

Dos jóvenes editoriales mexicanas nacidas a principios de los años 2000, Sexto Piso y Almadia, apoyaron esta reacción, y encargaron a traductores mexicanos la traducción de clásicos extranjeros, tales como el Portrait de Balzac, de Théophile Gautier, u obras de Henry James o Alberto Savinio. ${ }^{1}$

En Colombia, se percibió la misma insatisfacción en las palabras de Iván Hernández Arbeláez, director de la colección Cara y Cruz de la editorial colombiana Norma:

\section{En el caso de las traducciones, me parece que en oca- siones los traductores españoles creen que sólo existe el español de España; traducen de una manera irres- ponsable, ponen a los autores ingleses a hablar como si fueran escritores españoles, como si los hechos es- tuvieran ocurriendo en una barriada madrileña, y eso no deja de perturbar y de alterar los nervios del lector (apud Tipiani, 2013, p. 570).}

\section{5}

Ese descontento fue una de las razones por las que en los años 90 Hernández Arbeláez lanzó la colección Cara y Cruz en la que, al lado de obras colombianas, reeditó clásicos de la literatura universal en versiones de traductores colombianos o latinoamericanos. Numerosas editoriales del país han seguido el ejemplo de Norma (Orozco, 2000, p. 86), al punto que hoy en día Colombia exporta muchas más traducciones que en el pasado.

En Colombia, una iniciativa conjunta de la Caja de Compensación Familiar Comfama y del Metro de Medellín ha hecho realidad un proyecto novedoso que, aunque distinto del anterior, comparte el mismo afán por permitir que el público colombiano acceda a los clásicos de la literatura sin pasar por el prisma de las traducciones peninsulares. Con el objetivo de "democratizar y masificar el libro" (Restrepo, 2017), se creó en la década de 2000 la colección Palabras

1 Ver, por ejemplo, la declaración de misión de Sexto Piso en https://sextopiso.mx/esp/editorial 
Rodantes, cuyos libros circulan de manera gratuita entre los usuarios del sistema de transporte Metro de Medellín, y son devueltos luego de leídos para que lleguen a nuevos usuarios. Varios traductores colombianos fueron llamados dentro de este proyecto para retraducir clásicos de la literatura universal, como $E l$ principito, de Antoine de Saint-Exupéry; El spleen de Paris, de Charles Baudelaire; El pescador y su alma, de Oscar Wilde, etc. El objetivo de estas dos colecciones es proponer a un público colombiano (la colección Palabras Rodantes) o latinoamericano (caso de la colección Cara y Cruz) textos de la literatura extranjera de los que puedan apropiarse sin sentir extrañeza.

Interesa saber cuál fue el resultado de esa propuesta de nuevas traducciones: ¿cómo se caracterizan lingüísticamente esos textos? El aspecto lingüístico de la traducción en Colombia ha sido objeto de muy escasos estudios. Los trabajos dedicados a la historia de la traducción en este país se centran en el papel cultural y político de la traducción en épocas claves (principalmente las de la colonización o de la emancipación) (Bastin, 2003; Orozco, 2000), en el tipo de obras traducidas a lo largo de la historia, en la personalidad y la labor de los mismos traductores, en las iniciativas tomadas en el sector de la traducción literaria (Pulido y Tipiani, 2012), o en el grado de fidelidad de la traducción con la obra traducida (véase Bastin, 2003 y Orozco, 2000, para un periodo anterior, y Pulido y Tipiani, 2012, para fechas más recientes).

Solo se pueden conseguir informaciones globales, y de forma indirecta, gracias a los estudios dedicados a la historia de la lengua en América. Por ejemplo, Sánchez-Méndez (2003, pp. 428-443) muestra que, pese a la polémica que enfrentó a partidarios del nacionalismo lingüístico y puristas defensores de la unidad de la lengua a lo largo del siglo XIx, la norma culta basada en el español centropeninsular fue la que rigió el uso culto de la lengua en América Latina hasta mediados del siglo Xx. En efecto, aunque el derrumbe del imperio español haya favorecido la aparición de nuevos focos lingüísticos y, por lo tanto, de varias normas lingüísticas con distinto grado de prestigio, se puede considerar que la norma castellana culta sigue siendo hoy la más prestigiosa de todas, lo cual se debe, según Lope Blanch (1977), a dos circunstancias fundamentales: "el factor histórico, y [...] la diversidad de las normas hispanoamericanas" (p. 44). Estas circunstancias indican de manera indirecta cuál pudo ser el imaginario lingüístico de la mayoría de los traductores latinoamericanos, y en particular de los colombianos, durante décadas: aunque se trate de una hipótesis que estudios futuros tendrán que confirmar, es muy probable que hayan interiorizado de manera espontánea una obligación de traducir de manera "neutra", sin que las editoriales hayan formulado normas explícitas. Es lo que confirma el escritor Pere Gimferrer, aludiendo a traductores famosos, como Octavio Paz o Julio Cortázar, a quienes se podrían agregar Pablo Neruda o Jorge Luis Borges: ${ }^{2}$

\section{[...] durante mucho tiempo, las personas cultas que escribían o traducían adoptaban un estándar común tanto en España como en América. Era una convención que aceptaron personas como Octavio Paz o Julio Cortázar (Gimferrer, apud Navarro Arisa, 1999).}

Sin embargo, Gimferrer sugiere a continuación una evolución reciente que podría relacionarse con las iniciativas de las editoriales evocadas arriba: "Ahora hay escritores o traductores jóvenes que ya no respetan eso" (apud Navarro Arisa, 1999). Este giro lingüístico de la traducción ha sido poco investigado. Los estudios dedicados al periodo reciente de la traducción en América Latina desde un punto de vista lingüístico o examinan traducciones al español neutro (por ejemplo, Sundell, 2010; Díaz-Oyarzábal, 2017, y Vega, 2018), o comparan dos traducciones realizadas a ambos lados del

2 Aunque, según Sánchez-Méndez (2003, p. 429), el nacionalismo lingüístico del siglo xIx llegó en Argentina a unos extremos que seguramente han contribuido a crear un imaginario lingüístico diferente del de otros países latinoamericanos, esto no parece haber afectado la lengua de sus traducciones. Véase por ejemplo Las memorias de Adriano, traducidas por Cortázar (Yourcenar, 2011[1982]), o Un bárbaro en Asia, traducido por Borges (Michaux, 2001). 
Atlántico. Aun así, en estos últimos trabajos, los autores se limitan a identificar lo "americano" de las traducciones realizadas en América Latina. Tal es el caso de los trabajos de Gómez-Pablos (1999, 2001). En la conclusión del primer trabajo, la autora evoca, sin resolverlo, un problema que nos parece de mayor alcance: el de la aceptabilidad de dichas traducciones en el resto de América Latina: “ ¿es cierto que la versión argentina de la obra de Cotroneo se puede vender sin dificultad para un público mexicano? ¿cuántas modificaciones suplementarias serían necesarias?” (1999, p. 143).

Este punto es el que se va a investigar aquí en las traducciones realizadas hoy en día en Colombia en reacción a las traducciones peninsulares. ¿Toman la libertad de emplear marcas diatópicas, las cuales puedan dificultar su recepción en otros países del continente o se limitan a suprimir todo elemento lingüístico propio del español peninsular, de modo que puedan ser leídas por cualquier lector latinoamericano? Puede que el público a quien vaya dirigida la traducción influya de modo inconsciente en la lengua meta. Por eso es preciso examinar por separado traducciones dirigidas a lectores latinoamericanos en general y traducciones dirigidas a lectores colombianos en particular.

Con este fin, examinaremos en este artículo una traducción específicamente dirigida a un público colombiano; la traducción de la obra del escritor francés Albert Camus L'étranger (1942) por el docente y escritor colombiano Pablo Montoya, publicada en 2013 en la colección Palabras Rodantes.

\section{Método}

Se escogió como método la comparación de la traducción colombiana con la traducción al español peninsular de José Ángel-Valente (Camus, 2001). Para caracterizar las diferencias morfosintácticas desde un punto de vista diatópico, bastó consultar libros especializados: estos rasgos son en su gran mayoría panamericanos (con excepción del sistema pronominal y el voseo), poco numerosos y han sido objeto de descripciones pormenorizadas (se destaca Kany, 1976; Lipski, 1996; Vaquero de Ramírez, 1996). Para averiguar la extensión del uso de un vocablo en el territorio americano, se recurrió primero a los diccionarios, como el Diccionario de americanismos (2015); también a los diccionarios no contrastivos llevados a cabo por el proyecto de Augsburgo: Nuevo diccionario de colombianismos (1993), Nuevo diccionario de uruguayismos (1993), Diccionario del español de Argentina: español de Argentina-español de España (2002) y Diccionario del español de Cuba: español de Cuba-español de España (2003). Consultamos también la segunda edición del Diccionario de mexicanismos, publicado por la Academia Mexicana de la Lengua en 2010. A lo largo del artículo, estos diccionarios se mencionarán con las respectivas abreviaciones: DicAm, DicCol, DicUr, DicAr, DicCu y DicMex.

En segundo lugar, se consultaron estudios que comparan, de manera más o menos exhaustiva, el léxico de varios países latinoamericanos y de España (Molero Pintado, 2003; Moreno de Alba, 1992, 1995; y Haensch, 2001, 2002).

En tercer lugar, cuando los términos examinados no venían mencionados ni en los diccionarios ni en los artículos especializados, hubo que recurrir a otros dos medios para evaluar la extensión de un vocablo en América Latina. El corpus electrónico CREA de la Real Academia de la Lengua Española permite obtener datos precisos acerca del uso de un término en un país determinado, pero debe manejarse con mucha prudencia, ya que los distintos países de habla española no se ven representados en igual proporción. Por ese motivo, solo se pudieron someter al test los países más representados en el corpus (Argentina, Chile, Colombia, Cuba, España, México, Perú, Venezuela), los cuales corresponden más o menos a las zonas lingüísticas tradicionales.

En cuarto lugar, está la encuesta a informantes hispanófonos, que se utilizó solo cuando los demás recursos no arrojaron resultados satisfactorios, 
pues se advierte el riesgo de que brinde resultados más representativos de un idiolecto (forma de hablar característica de cada persona, la cual "depende de la cultura general y de la trayectoria personal de cada uno", Haensch, 2002, p. 56) que de una variedad dialectal. Dicha encuesta contó con la participación de cuatro informantes españoles y veinticuatro latinoamericanos - cuatro representantes por cada uno de los siguientes países: Colombia, México, Argentina, Venezuela, Chile y Perú-. Los informantes, de ambos sexos, se encontraban en un rango de edades entre 30 y 50 años, con nivel de escolaridad medio (pregrado como mínimo). El test se presenta en la Tabla 1. Sin más informaciones, se pidió a los informantes que indicaran cuál de las dos opciones se empleaba en su país de procedencia, o cuál era más frecuente o más formal que la otra.

Por los motivos que se detallaron anteriormente, empezaremos por mencionar los resultados obtenidos en lo relativo a la morfosintaxis. Luego se presentarán de manera más pormenorizada los resultados obtenidos en el aspecto léxico.

\section{La morfosintaxis}

Los rasgos morfosintácticos que singularizan la traducción colombiana con respecto a la traducción peninsular son todos o panamericanos o propios del español de un grupo de países latinoamericanos:

- Verbo: preferencia por las formas simples de la conjugación, y en particular el uso del pretérito indefinido en lugar del pretérito perfecto; uso exclusivo de las formas del imperfecto del subjuntivo en -ra y no en -se; uso conjugado del verbo unipersonal "haber" (aunque Vaquero de Ramírez —1998, pp. 29-30—, señale ese uso como más oral, como en "me quedaba esperar que hubieran muchos espectadores el día de mi ejecución”, como dice Montoya en Camus, 2013, p. 96); uso de la voz pasiva cuando la traducción española prefiere la voz activa; preferencia por las formas reflexivas de los verbos, en particular uso sistemático de la forma "reírse" cuando la traducción española emplea "reír"; uso del verbo "deber" en lugar de la locución verbal "deber de" del español peninsular, etc.

- Adverbio: empleo de las formas largas de los adverbios de lugar "adelante", "afuera" para expresar estado o situación (Kany, 1976, p.325), en lugar de las formas cortas empleadas en español peninsular; sustitución de la preposición "por" del español peninsular por "en" en las locuciones adverbiales "en la tarde", "en la noche”, una sustitución que también ocurre en Chile, México y Venezuela, mientras que en Uruguay se usa la preposición "de" ("de tarde") (Molero, 2003, pp. 88-89).

- Pronombres: uso sistemático de "lo" para el acusativo del pronombre personal de la tercera persona del singular referido a personas cuando el español peninsular usa "le" (fenómeno conocido como "leísmo")

- Preposiciones: empleo de "donde" seguida de nombre propio ("No quería almorzar donde Celeste como era mi costumbre”, Montoya en Camus, 2013, p. 38) como equivalente de la locución "en casa de", "en la tienda/el restaurante/la oficina de” del español peninsular. Kany (1976, pp. 422-423) registra el empleo de la preposición "donde" seguida de nombre propio en América, mientras que Haensch (2002, p. 42) afirma que este uso está documentado en Chile, Perú, Ecuador, Colombia, Venezuela, toda Centroamérica y República Dominicana. También se nota el empleo de la locución preposicional "arriba de" "Arriba de su cama, hay un ángel de estuco blanco”, Montoya en Camus, 2013, p. 47) que Kany (1976, p. 402) describe como poco frecuente en español peninsular, únicamente presente en el habla popular de las regiones rurales de España.

- Diminutivos: uso del sufijo diminutivo -ico, propio del español de Colombia y de los países de América central ("un reguero de goticas", Montoya en Camus, 2013, p. 46). 
- estructuras comparativas en "entre más... más" ("Así, entre más reflexionaba, más cosas desconocidas y olvidadas sacaba de mi memoria”, Montoya en Camus, 2013, p. 104) en lugar de “cuanto más... más” del español peninsular.

Los libros dedicados a la morfología y a la sintaxis del español de América no mencionan la construcción; sin embargo, el cuestionario realizado a los informantes latinoamericanos indica que se usa en varios países: de 24 participantes, 14 escogieron de manera exclusiva "entre más... más", 7 aceptaron ambas construcciones, señalando a veces "cuanto más... más" como más formal, y solo 4 escogieron "cuanto más... más”.

\section{El léxico}

El criterio tomado en cuenta para clasificar los vocablos que Montoya no tradujo de la misma manera que Ángel-Valente fue, primero, el grado de distancia con el español peninsular: por un lado, están los términos que no existen en español peninsular o que tienen otro sentido en esta variante; por otro lado, están los términos que existen en español peninsular, pero cuyo uso es mucho menos frecuente en esta variante (lo que llamaremos "costumbres léxicas”). Una vez hecha esta primera clasificación, el objetivo era medir el grado de extensión en América Latina de estos dos tipos de vocablo usados por Montoya. De ahí una subdivisión del primer grupo de términos entre colombianismos y americanismos, y del segundo grupo entre costumbres léxicas colombianas o americanas. De ahí por fin, una clasificación de los americanismos en función de su extensión geográfica: los americanismos serán considerados de "baja extensión" si solo están documentados en América central o si están presentes en menos de cinco países, entre los cuales haya algunos de América Central; de "gran extensión" si están presentes en al menos tres cuartas partes de los países latinoamericanos; y de "mediana extensión” cuando se documenten en cuatro a seis países por fuera de América central, es decir en países más grandes y poblados.

\author{
Vocablos que no existen en español \\ peninsular o tienen un sentido distinto en \\ esta variante
}

\section{Colombianismos}

Aplicando la definición de americanismo dada por Haensch (2001), el colombianismo se podrá definir como elemento léxico presente en el español de Colombia, que difiere de la existencia o del uso del español de otros países latinoamericanos (p. 77). Así, se tienen que distinguir los colombianismos "estrictos", privativos de Colombia, y los "relativos", vocablos que existen en otros países latinoamericanos, pero tienen en Colombia una acepción particular y exclusiva.

En la traducción de Montoya, solo se encontró un colombianismo, de tipo estricto: el término "chanda" (Camus, 2013, p. 43), como equivalente de la palabra francesa salaud (Camus, 1942, p. 46), que Ángel-Valente traduce por "cabrón” (Camus, 2001, p. 32). Este vocablo lo define el Diccionario de americanismos (1993, s. v. "chanda") como regionalismo de uso en el oeste y el suroeste de Colombia, con tres acepciones: "1. Sarna. 2. Perro que no es de raza. 3. Cosa fea y de mala calidad". De las dos primeras se deduce el sentido argótico del término en la traducción de Montoya. De hecho, ninguno de los informantes colombianos (bogotanos o costeños) lo conocía. Este vocablo podría, pues, plantear problemas de comprensión a lectores latinoamericanos de otros países, pero también a una mayoría de lectores colombianos.

\section{Americanismos}

Haensch (2001) define el americanismo como "elemento léxico presente en el español de América que difiere de la existencia o del uso del español de España” (p. 77). Cabe diferenciar estas dos variantes como americanismo "estricto" y americanismo "relativo", respectivamente con el objetivo de determinar el grado de extensión en América Latina de los americanismos presentes en la traducción de Pablo Montoya. La tarea se dificultó por el hecho 
de que algunos vocablos o locuciones no aparecen en el Diccionario de americanismos, con lo cual se tuvo que recurrir al test, necesariamente no exhaustivo.

\section{Americanismos estrictos}

Haensch (2002) llama "panamericanismos" o "americanismos generales" a los americanismos estrictos usados en toda América Latina (p. 50). En la traducción de Pablo Montoya, solo encontramos un americanismo de este tipo: "papa" (Camus, 2013, p. 45), que se refiere a lo que los españoles llaman "patata", vocablo empleado en la traducción española (Ángel-Valente en Camus, 2001, p. 31).

Se presentan a continuación los demás americanismos estrictos presentes en la traducción de Montoya, según su grado de extensión en América Latina.

- Para la gifle del texto francés (Camus, 1942, p. 61), Pablo Montoya empleó "cachetada" (Camus, 2013, p. 69), término aceptado por la totalidad de los informantes latinoamericanos y rechazado por todos los informantes españoles, aunque el Diccionario de la lengua española de la RAE la menciona con esa acepción; en España se usa más bien "bofetada", término escogido por el traductor español (Camus, 2001, p. 41). Aunque el Diccionario de americanismos no menciona "cachetada" sino "cacheteada", de uso en Guatemala, Colombia, Ecuador, Argentina y Uruguay, el término fue aceptado por todos los informantes latinoamericanos (a veces compite con "bofetada", señalada como más formal).

Moreno de Alba señala por su cuenta (1992, p. 110) que "cachete" es la voz que predomina en América Latina, aunque también se emplea "mejilla" en varios países. "Cachetada" no tendría la misma extensión que "cachete", pues, por ejemplo, el DicCu no menciona "cachetada", sino solamente "cachetón” y "cachetudo". Según el DicMex, "cachete" tendría en México el sentido de "nalgas", de ahí "cachetón" ("de glúteos grandes”); en México, "cachetada” en el sentido de "bofetada" solo aparecería en la expresión "cachetada guajolotera" ("bofetada dada para espabilar a alguien") (DicMex: s. v. "cachetada"). Aunque sea difícil determinar la extensión de uso del término "cachetada", se puede afirmar que, dada la extensión de "cachete" en una mayoría de países latinoamericanos, la palabra "cachetada" no plantearía problemas de comprensión.

- La locución verbal "tocar la puerta" empleada en la traducción colombiana (Montoya en Camus, 2013, p. 58) no existe en España, donde se usa "llamar a la puerta", expresión empleada por el traductor español (Ángel-Valente en Camus, 2001, p. 41). Resulta complicado determinar la extensión de uso de la locución en la medida en que no viene mencionada en los diccionarios. Sin embargo, fue la locución exclusivamente escogida por la totalidad de los informantes latinoamericanos, con lo cual se podría calificar de americanismo de gran extensión.

- Para la locución verbal francesa avoir l'air + adjetivo, que indica "calidad", el traductor colombiano escogió de manera sistemática la locución "verse + adjetivo" : "Se veía cansado" (Montoya en Camus, 2013, p. 93), "Raymond se veía sombrío" (Camus, 2013, p. 44). El traductor español, en cambio, escogió o el verbo "parecer + adjetivo" o la locución "tener un aire + adjetivo": "Parecía muy fatigado" (Ángel-Valente en Camus, 2001, p. 74), "Raymond tenía un aire muy sombrío" (Camus, 2001, p. 58). La locución "verse + adjetivo" fue rechazada por los tres informantes españoles y escogida de manera exclusiva por quince informantes latinoamericanos, mientras que cinco aceptaron las dos expresiones, señalando "parece + adjetivo" como más formal. Finalmente, solo cuatro informantes (dos peruanos, dos argentinos y un venezolano) escogieron "parecer + adjetivo". De lo cual se puede deducir que la expresión "verse + adjetivo" es un americanismo de gran extensión.

- Para traducir el francés marchand de tabac (Camus, 1942, p. 37) o bureau de tabac (Camus, 1942, p. 78), Pablo Montoya emplea los vocablos 
“cigarrero" y "cigarrería” (Camus, 2013, pp. 40, 70), cuando el traductor español emplea "estanquero" y "estanco" (Ángel-Valente en Camus, 2001,pp. 27,51).Según el Diccionario de americanismos (2015, s. v. "cigarrería"), la voz "cigarrería" estaría documentada en República Dominicana, Perú, Argentina, Uruguay, Chile, y en el oeste de Ecuador. No menciona Colombia, aunque la voz sea usual en este país, según lo indicaron los informantes colombianos. Se trata, pues, de un americanismo de mediana extensión que, dada su transparencia, podría ser entendido por un lector latinoamericano de otro país.

- El vocablo "tiquete" (de bus, en este caso) presente en la traducción colombiana (Camus, 2013 , p. 20) es el que usan los colombianos para referirse a lo que los españoles llaman "billete” (Ángel-Valente en Camus, 2001, p. 11). El Diccionario de americanismos lo indica como usual en América Central (Guatemala, Honduras, El Salvador, Nicaragua, Costa Rica, Panamá), así como en Colombia, Ecuador y en el este de Bolivia. Molero (2003, pp. 50-51) señala en los demás países la palabra "boleto" (Argentina, Uruguay, México, Venezuela, Chile). Moreno de Alba (1992) indica el anglicismo ticket en varios países de América central y "pasaje" en República Dominicana, Venezuela, Perú y Chile (p. 124). Se trata, entonces, de un americanismo presente sobre todo en América Central y en la zona noroeste de América del Sur. El hecho de que se trate de un anglicismo no plantearía mayores problemas de comprensión para un lector latinoamericano.

- La locución "vestido de baño" empleada en la traducción colombiana (Camus, 2013, p. 70) es la más común, según el Diccionario de americanismos, en Nicaragua, Costa Rica, Colombia y Ecuador. Moreno de Alba añade Honduras a la lista (1992, p. 113). En Colombia, la palabra coexiste con "traje de baño", la cual también se usa en México, Venezuela, Chile, Uruguay, Puerto Rico y República Dominicana. En España se usa comúnmente "bañador" (Ángel-Valente en
Camus, 2001, p. 51), pero "vestido de baño" no se usa, y "traje de baño" solo se emplea en contextos más genéricos ("Ofertas en trajes de baño"). Aunque se trate de un americanismo de poca extensión (tres países de América Central más Colombia y Ecuador), no parece que este pueda originar problemas de comprensión, por su proximidad con la otra locución (traje de baño) y por su relativa transparencia.

- Para el café noir del libro francés (Camus, 1942, p. 16), el traductor español usó "café solo" (ÁngelValente en Camus, 2001, p. 15) mientras que el traductor colombiano usó "café negro" (Montoya en Camus, 2013, p. 23), expresión aceptada de manera exclusiva por 12 de los 24 informantes latinoamericanos, de manera exclusiva o junto a "café solo" (en Colombia, Venezuela, México y Perú. El Diccionario de americanismos (2015, s. v. "café") documenta la expresión en República Dominicana y Puerto Rico, mientras que Molero (2003, pp. 48-49) la señala como usual en Argentina; y, en cambio, indica "cafe'" a secas para Chile, México y Uruguay y "negrito" en Venezuela. Los datos no concuerdan y lo único que se puede concluir es que la expresión "café negro" no está extendida en toda América Latina. Sin embargo, dada su transparencia, no plantearía ningún problema de comprensión.

- Por otro lado, resultó difícil determinar el grado de uso de la expresión "al otro día", empleada por Pablo Montoya (Camus, 2013, p. 86) en lugar de "al día siguiente", presente en la traducción española (Ángel-Valente en Camus, 2001, p. 68). En América Latina se puede usar el adjetivo "otro, a" en lugar de "siguiente" en locuciones adverbiales temporales como "al otro día”. De los 24 informantes latinoamericanos, 12 escogieron la locución "al otro día" en detrimento de "al día siguiente”, 8 aceptaron ambas locuciones, pero señalaron "al día siguiente" como más formal y solo 4 informantes escogieron "al día siguiente". El test en CREA matiza esta información, ya que revela una proporción mucho más elevada de la 
otra expresión en todos los países examinados. Sin embargo, la expresión "al otro día" existe en estos países, salvo en Perú, donde la proporción es casi la misma que en España, es decir, casi nula (Figura 1).

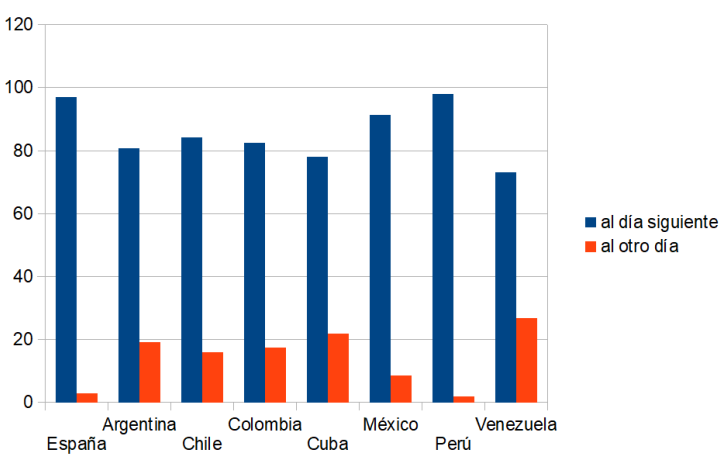

Figura 1 Extensión geográfica de las expresiones “al día siguiente"/“al otro día”

- La lexía compleja "comer un pedazo" empleada en la traducción colombiana (Montoya en Camus, 2013, p. 47) como equivalente de la expresión francesa manger un morceau (Camus, 1942, p. 47) parece ausente del español peninsular, donde se usaría más "tomar un bocado" (Ángel-Valente en Camus, 2001, p. 33). Solo 6 (3 colombianos, 2 chilenos y 1 peruano) de los 24 informantes latinoamericanos aceptaron la expresión "comer un pedazo", mientras que los 18 restantes rechazaron por igual las dos expresiones. Además, no aparece en ninguno de los diccionarios, lo cual lleva a concluir que se trata de un americanismo de poca extensión.

- Los "emparedados" de la traducción colombiana (Montoya en Camus, 2013, p. 126) no fueron aceptados por todos los informantes colombianos, ni por todos los informantes latinoamericanos. Aunque aparezca en el Diccionario de la lengua española ("porción pequeña de jamón u otra vianda, entre dos rebanadas de pan de molde", Real Academia Española, 1998, s. v. "emparedado"), la palabra no se usa en España. Tampoco parece ser de uso muy extendido en América Latina. De hecho, ni el Diccionario de Americanismos ni los diccionarios no contrastivos consultados la mencionan. Solo tres informantes latinoamericanos (entre los cuales hubo dos colombianos y un peruano) la señalaron como usual; otro informante colombiano comentó que el término se usaba en las películas traducidas en México y traídas a Colombia. Ahora bien, ninguno de los informantes mexicanos lo aceptó, con lo cual resultan inciertos el origen y la extensión de esta palabra en América Latina, y si plantea problemas de comprensión, no será por su estatuto de americanismo de poca extensión. En cuanto a la voz "bocadillo" empleada en la traducción española (Ángel-Valente en Camus, 2001, p. 100), o no se usa en América Latina, o remite, en Venezuela y Colombia, a otra realidad, "dulce de guayaba conservado en corta cantidad y envuelto en hojas de plátano" (Real Academia Española, 1998, s. v. "bocadillo").

De lo que precede, se puede afirmar que a excepción de los términos "chanda" y "emparedado", muy pocos términos plantearían problemas de comprensión a un lector latinoamericano no colombiano, pues aunque la mayoría de los americanismos empleados por Pablo Montoya no son panamericanos, son lo suficientemente transparentes como para no impedir la comprensión.

\section{Americanismos relativos}

Los americanismos que llamamos "relativos" resultaron más numerosos. También se intentó clasificarlos en función de su grado de extensión en América Latina.

Encontramos dos americanismos, de alcance panamericano: el verbo "voltearse" y la locución verbal "tener ganas de".

- El verbo "voltearse" (Camus, 2013, p. 114) en lugar del verbo "volverse" escogido por el traductor español (Camus, 2001, p. 90). El DicAm señala esa acepción de "voltearse" ("Girar la cabeza o el cuerpo hacia atrás", Asociación de Academias de la lengua española, 2015, s. v. "voltearse") como panamericana. En España, “voltearse” tiene el sentido de "dar vueltas, cayendo y rodando por ajeno 
impulso o voluntariamente y con arte, como lo hacen los volteadores" (Real Academia Española, 1998, s. v. "voltear").

- La locución verbal "tener ganas de" (Montoya en Camus, 2013, p. 45) por supuesto existe en el español de España, pero o produce el efecto de un deseo muy fuerte y casi imperioso ("tengo ganas de ir al cine") o sirve para expresar una necesidad ("tengo ganas de vomitar"). En el contexto presente ("J'ai voulu fumer une cigarette à la fenêtre mais l'air avait fraîchi et j'ai eu un peu froid"), el español peninsular emplearía preferiblemente el verbo "apetecer", tal como lo hace Ángel-Valente (Camus, 2001, p. 29): "Me apeteció fumar un cigarrillo en la ventana [...]”. En América Latina donde casi no se emplea "apetecer", la locución "tener ganas" sirve tanto para una simple apetencia como para un deseo imperioso o una necesidad.

- La palabra “aviso" empleada en la traducción colombiana (Camus, 2013, p. 39) como equivalente de la palabra francesa réclame (Camus, 1942 , p. 36) se refiere a realidades muy distintas ("Indicio, señal", "Precaución, atención, cuidado", "prudencia, discreción”, Real Academia Española, 1998, s. v. "aviso") en España, donde la palabra usual es "anuncio" (Camus, 2001, p. 26). "Aviso" en el sentido de "soporte visual o auditivo en el que se transmite un mensaje publicitario" (Asociación de Academias de la lengua española, 2015, s. $v$. "aviso") solo sería inusual, según el DicAm, en Cuba, República Dominicana, Costa Rica y Puerto Rico. Haensch (2002, p. 50), por su parte, lo clasifica entre los americanismos generales o panamericanismos. Se trata, pues, de un americanismo de gran extensión que no debería plantear ningún problema de comprensión.

- Así mismo, la palabra "lentes" empleada en la traducción colombiana (Montoya en Camus, 2013 , p. 110) en lugar de las "gafas" de la traducción española (Ángel-Valente en Camus, 2001, p. 87) es, según el DicCol (1993, s. v. "lente") de uso común en la Costa Atlántica de Colombia. El DicAm no menciona la palabra, pero
Molero (2003, pp. 40-41) la señala como usual en Venezuela y Uruguay y de uso tan frecuente como "anteojos", en Argentina, México y Chile. Una búsqueda en CREA confirma que "gafas" es más frecuente que "lentes" en Colombia (54 contra 31 ocurrencias), mientras que en Chile y Perú se usa más "lentes" (29 contra 17 ocurrencias en Chile, 20 contra 8 ocurrencias en Perú). De todas maneras, el término parece usual, aunque en proporciones distintas, en muchos países latinoamericanos.

- Si bien no es totalmente panamericana, la palabra "vitrina" empleada en la traducción colombiana (Montoya en Camus, 2013, p. 70) es, según Moreno de Alba (1992, p. 114)3 la más común en muchas capitales latinoamericanas en lugar del peninsular "escaparate" (Ángel-Valente en Camus, 2001, p. 51). En España, la palabra "vitrina" se usa con otro sentido: "Mueble acristalado y con estantes para exponer y proteger objetos o productos" (Real Academia Española, 1998, s. v. "vitrina"). En la traducción colombiana, la palabra "escaparate" aparece en cambio para referirse a lo que el español peninsular llama "armario"; es, según el DicAm, un término usado en Colombia, Cuba, República Dominicana y Venezuela. De hecho, el DicCol la señala con esa acepción: "armario en que se guarda la ropa" (Haensch y Werner, 1993, s. v. "escaparate”).

- El verbo "botar" (“botar el agua") empleado en la traducción colombiana (Montoya en Camus, 2013, p. 55) en el sentido de "tirar, dejar caer algo o a alguien” (Asociación de Academias de la lengua española, 2015, s. v. "botar") no se emplea con esa acepción en España, donde tiene el sentido de "rebotar" si se trata de un balón o de "cambiar de dirección por chocar con otro cuerpo duro" (Real

3 Moreno de Alba (1992, p. 114) explica, sin embargo, que en ciudades como Panamá, Santo Domingo, La Habana, Buenos Aires y Montevideo se dice vidriera, mientras que en la Ciudad de México, Lima y Managua es más frecuente el uso de aparador y en Caracas predomina exhibidor. 
Academia Española, 1998,s.v. "botar") si se trata de un cuerpo elástico. La acepción que tiene la palabra en la traducción colombiana es, según el DicAm, usual en una gran mayoría de países latinoamericanos. Solo sería inusual en Uruguay, Paraguay y en Argentina (excepto en la zona noroeste).

- Tampoco ha de plantear problemas de comprensión el vocablo "carro" en la expresión "carro de la funeraria” de la traducción colombiana (Montoya en Camus, 2013, p. 23) en lugar del peninsular "coche" ("coche funerario", Ángel-Valente en Camus, 2001, p. 14) para remitir al corbillard francés (Camus, 1942, p. 15). Según Molero (2003, pp. 52-53) y Moreno de Alba (1992, p. 114), "carro" sería la única palabra empleada en una mayoría de países latinoamericanos (Sur y norte de México, Guatemala, Honduras, El Salvador, Nicaragua, Panamá, Cuba, República Dominicana, Puerto Rico, Colombia, Venezuela y Perú). En Perú, el vocablo alternaría con "auto", única palabra empleada en Argentina, Uruguay y Chile. En México y Paraguay, se podrían emplear tanto "coche" como "carro" y "auto". En España, el término "carro" remite, en cambio, a cierto tipo de carruaje. Se trata, pues, de un americanismo de gran extensión que solo podría plantear problemas de comprensión a lectores argentinos, uruguayos o chilenos; sin embargo, siendo una palabra perteneciente al vocabulario cotidiano muy presente en las películas y series, podemos imaginar que hasta los lectores de esos tres países la entenderían.

- El verbo "coger" tiene una acepción sexual, la de "realizar el coito el hombre" (Asociación de Academias de la lengua española, 2015, s. v. "coger"), en muchos países latinoamericanos: según el Dic Am en México, Guatemala, Honduras, El Salvador, Nicaragua, Costa Rica, Panamá, República Dominicana, Venezuela, Argentina, Uruguay y Bolivia, países a los que Haensch (2002, p. 47) añade Paraguay. Por eso se le prefiere muy a menudo "tomar", tal como ocurre en la traducción colombiana, aunque "coger" es usual en Colombia con el sentido peninsular:
(1) [...] j'ai pris un vieux journal et je l'ai lu. (Camus, 1942, p. 36)

[...] tomé un viejo periódico y lo leí. (Montoya en Camus, 2013, p. 39)

[...] cogi un viejo periódico y lo leí. (Ángel-Valente en Camus, 2001, p. 26)

Esa sustitución es responsable de los desplazamientos semánticos que se pueden observar en los enunciados siguientes y sus traducciones:

(2) Il lui a cité des exemples de chiens qui avaient fait des dizaines de kilomètres pour retrouver leur maître. Malgré cela, le vieux a eu l'air plus agité. “[...] Les agents le prendront, c'est sûr." (Camus, 1942, p. 63)

Le citó ejemplos de perros que luego de recorrer decenas de kilómetros habían vuelto adonde su dueño.

A pesar de ello, el viejo se agitó más. “(...) Los agentes lo agarrarán con seguridad." (Montoya en Camus, 2013, p. 60)

Le citó ejemplos de perros que habían recorrido decenas de kilómetros para encontrar a su amo. A pesar de eso, el viejo todavía se excitó más. “[...] Los guardias lo cogerán, seguro." (Ángel-Valente en Camus, 2001, p. 43)

Cuando el verbo "coger" no es sustituible por "tomar", como aquí, se suele sustituir en América Latina por el verbo "agarrar", el cual se emplea más en España con la acepción de "asir fuertemente" (Real Academia Española, 1998, s. v. "agarrar”). Si en América Latina se quiere expresar la idea de “asir fuertemente", se podrá recurrir al verbo “apretar", como en el enunciado siguiente:

(3) Moi, naturellement, j’ai serré le revolver de Raymond dans mon veston. (Camus, 1942, p. 92)

Naturalmente, apreté el revólver de Raymond en mi chaqueta. (Montoya en Camus, 2013, p. 82)

Yo, naturalmente, agarré el revólver de Raymond en mi chaqueta. (Ángel-Valente en Camus, 2001, p. 61)

- La palabra "canasta" empleada por el traductor colombiano (Montoya en Camus, 2013, p. 99) es de uso frecuente en América Latina para referirse a lo que llaman "cesta" en España, vocablo presente en la traducción española (Ángel-Valente en Camus, 2001, p. 79). La palabra viene mencionada en el DicCol, pero con una acepción distinta: "enredaje metálico sobre la cubierta de un 
vehículo automotor" (Haensch y Werner, 1993, s. v. "canasta") y el DicAm señala la misma acepción en Costa Rica y República Dominicana. También señala otra acepción en Colombia y República Dominicana: “Caja, generalmente de plástico, dividida en compartimentos para transportar bebidas embotelladas". (Asociación de Academias de la lengua española, 2015, s. v. "canasta"). En el DicAm, es la palabra "canasto" la que, en Panamá, República Dominicana, Bolivia y Argentina, parece corresponder con el significado del término empleado por Montoya: "Recipiente, especialmente de mimbre o alambre, utilizado para arrojar papeles inservibles u otros desperdicios" (Asociación de Academias de la lengua española, 2015, s. $v$. "canasto"). Sin embargo, la mayoría de los informantes latinoamericanos (19) rechazaron "cesta" a favor de "canasta" y 4 aceptaron ambos términos; solo dos escogieron "cesta" de manera exclusiva. Con lo cual se puede concluir a un americanismo de gran o mediana extensión.

- El "saco" de la traducción colombiana (Montoya en Camus, 2013, p. 136) es la palabra usada en varios países latinoamericanos para referirse a lo que el español peninsular denomina "chaqueta", vocablo presente en la traducción española (Ángel-Valente en Camus, 2001, p. 108), o "americana”. Según los informantes colombianos, tanto "saco" como "chaqueta" se pueden usar en Colombia. Según Molero (2003, pp. 32-33), "saco" alternaría con blazer en Argentina, México, Uruguay y Venezuela (donde también existe "paltó"), mientras que, en Chile, "chaqueta” y "vestón” se emplearían por igual. En España, "saco" se refiere o a realidades totalmente distintas $^{4} \mathrm{o}$ a prendas distintas de la "chaqueta" peninsular. 5 Se trata de un americanismo de

4 “1. Receptáculo de tela, cuero, papel etc., por lo común de forma rectangular o cilíndrica, abierto por uno de los lados"; "2. persona o cosa que incluye muchas otras en sí". (Real Academia Española, 1998, s. v. "saco")

5 Vestidura tosca y áspera de paño burdo o sayal"; "Especie de gabán grande y, en general, vestidura holgada que no mediana extensión que, por lo tanto, podría plantear problemas de comprensión a ciertos lectores latinoamericanos.

Para traducir el francés pièce (Camus, 1942, pp. 13, 17, 24, etc.), el traductor colombiano escoge a veces “cuarto" (Montoya en Camus, 2013, p. 38), término que existe en español peninsular junto a "habitación" (Ángel-Valente en Camus, 2001, p. 13); más a menudo, escoge "pieza" (Montoya en Camus, 2013, pp. 22, 25, etc.), término que el Diccionariodelalenguaespañolaseñalacon esaacepción (Real Academia española, 1998, s. v. "pieza") pero que es en realidad inusual con ese sentido en España, donde se refiere más bien a un "pedazo o parte de una cosa”, una moneda de metal, una obra teatral entre otros. Aunque el Dic Am solo menciona otra acepción del término, el DicCol señala la palabra con esa acepción en dos regiones de Colombia (Antioquia y Caldas): "Cada uno de los departamentos en que se divide una casa" (Haensch y Werner, 1993, s. v. "pieza"). El DicUr y el DicAr también la señalan como usual, lo que confirma Molero (2003, pp. 6-7), quien indica que la palabra también es de uso en Chile donde, sin embargo, se refiere más al "dormitorio" del español peninsular. Dado que la palabra no aparece en el DicAm, resulta difícil determinar el grado de ocurrencia en América Latina, pero no parece ser un americanismo de extensión tan importante como los precedentes.

La traducción de Pablo Montoya ofrece varias ocurrencias de la locución verbal "tocarle a uno hacer algo" para traducir la noción de necesidad que el español peninsular expresa con las locuciones "tener que" o "ser necesario que":

(4) [...] parce qu'il a fallu que je monte chez Emmanuel (Camus, 1942, p. 9)

[...] porque me tocó subir a casa de Emmanuel (Montoya en Camus, 2013, p. 18)

se ajusta al cuerpo"; "vestido corto que usaban los antiguos romanos, excepto los varones consulares, en tiempo de guerra" (Real Academia Española, 1998, s. v. "saco"). 
[...] porque fue necesario que subiera a casa de Emmanuel (Ángel-Valente en Camus, 2001, p. 10)

Esta locución verbal es de uso muy frecuente con ese sentido en Colombia y, al parecer, en varios países de América Latina: de los 24 informantes latinoamericanos, 6 escogieron "tocarle a uno hacer algo" de manera exclusiva (3 venezolanos, 2 argentinos y un colombiano), 5 aceptaron las dos expresiones, 9 escogieron "tener que" en detrimento de la otra y 4 no escogieron ninguna. Como la expresión no aparece en los diccionarios especializados, resultó difícil determinar la extensión de su uso, mediana al parecer. En España, la locución se emplea con un sentido ligeramente distinto: "corresponder a alguien cierta obligación en un reparto de ellas. 'A mí me toca poner la mesa." (Moliner, 2004, s. v. "tocar").

Por fin la palabra "correa" empleada por Montoya (Camus, 2013, p. 103) en lugar del "cinturón" (Ángel-Valente en Camus, 2001, p. 81) del espaEspaña: "Tira de cuero u otro material que sirve para atar, ceñir o colgar” (Real Academia española, 1998, s. v. "correa"). La palabra "correa" coexiste en Colombia con "cinturón”. Aunque ausente del DicAm y de los diccionarios no contrastivos, fue aceptada por todos los informantes venezolanos (a diferencia de "cinturón" que fue excluido al remitir al cinturón de seguridad en Venezuela), por todos los informantes colombianos y peruanos al igual que "cinturón". En cambio, los chilenos, los mexicanos y los argentinos rechazaron el término, con lo cual el término parece ser de mediana extensión.

Pablo Montoya (Camus, 2013, p. 19) traduce el bureau francés (Camus, 1942, p. 10) por "oficina" cuando la traducción española usa "despacho" (Ángel-Valente en Camus, 2001, p. 10). En España, la "oficina" remite al "sitio donde se trabaja escribiendo, haciendo cuentas etc." (Moliner, 2004, s. v. "oficina"), y una oficina puede estar compuesta de varios "despachos", "habitación en una oficina destinada al trabajo de determinado

jefe o empleado y a que reciba las visitas" (Moliner, 2004, s. v. "despacho"). En Colombia, se observa que el vocablo "oficina” remite tanto a lo que el español peninsular llama "oficina" como a lo que designa "despacho". Esa particularidad no aparece en los diccionarios, y para averiguar la situación en los demás países latinoamericanos, no se tuvo más opción que realizar una prueba en el corpus electrónico CREA de la Real Academia, anticipando que en los países en los que la palabra "oficina" tiene las dos capacidades, la proporción de empleos de dicha palabra había de ser mucho más elevada, lo cual se observó solo en Colombia, Chile, Cuba y Guatemala (Figura 2).

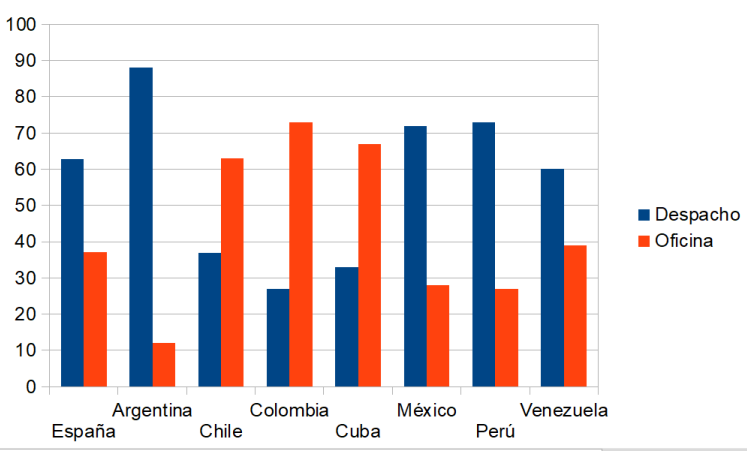

Figura 2 Extensión geográfica de los vocablos "despacho" /"oficina"

"Oficina" es un americanismo de poca extensión, pero teniendo en cuenta que el matiz referencial al que remite la pareja de términos es muy leve, no plantearía ningún problema de comprensión fuera de Colombia.

\section{Vocablos de uso más frecuente en América Latina que en España}

El análisis de las dos traducciones reveló otro tipo de discrepancia léxica. Ocurrió muy a menudo que el traductor colombiano empleó una palabra que existe en España, pero con una frecuencia mucho menor. Se podría calificar este fenómeno como "costumbre léxicas”. El test lingüístico a los informantes latinoamericanos y el corpus electrónico CREA de la RAE fueron muy a menudo los únicos métodos válidos para averiguar si las voces o expresiones presentes en la traducción colombiana correspondían a 
Tabla 1 Costumbres léxicas españolas y latinoamericanas

\begin{tabular}{llll}
\hline Traducción colombiana & América Latina & Traducción española & España \\
\hline $\begin{array}{l}\text { prender un cigarrillo, la } \\
\text { luz, etc. }\end{array}$ & prender/encender & encender & encender/prender \\
pedazo & pedazo/trozo & trozo & trozo/pedazo \\
agregar que & agregar que/añadir que & añadir que & añadir que/agregar que \\
morgue & morgue & depósito & depósito/morgue \\
después del almuerzo & después del almuerzo/ & después de comer & después de comer/después \\
& después de comer & & del almuerzo \\
hermosa/bella (mujer) & hermosa/bella/guapa & guapa/hermosa & guapa/hermosa/bella \\
café & café/marrón & marrón & marrón/café \\
suburbio & suburbio/afueras & afueras & afueras/suburbio \\
\hline
\end{tabular}

costumbres específicamente colombianas o a costumbres americanas (o parcialmente americanas), ya que en general los diccionarios no mencionan este tipo de costumbres.

En la Tabla 1, están consignados los resultados de esta investigación: no se encontró ninguna "costumbre léxica” que fuera específicamente colombiana, sino únicamente costumbres léxicas compartidas por varios países latinoamericanos. En negrita se indica la voz mayoritariamente empleada en la variedad regional considerada. Si dos voces se emplean más que otra, se subraya la más empleada de las dos.

El verbo "prender" empleado por Montoya en el sintagma "prendió un cigarrillo" (Camus, 2013, p. 52) solo se usa en España cuando se trata del fuego ("prender fuego", "prender una fogata"), y se prefiere "encender" (Ángel-Valente en Camus, 2001, p. 36) para la luz, el cigarrillo, la radio, etc. El DicAm no menciona esa acepción americana del verbo "prender" pero de los 24 informantes latinoamericanos, 4 aceptaron los dos verbos, mientras que 20 escogieron "prender" en detrimento de "encender". Ninguno escogió "encender" en detrimento de "prender". Esas proporciones parecen indicar un americanismo de gran extensión.

Aunque también exista en España, parece que el término "pedazo" escogido por el traductor colombiano (Montoya en Camus, 2013, p. 40) es menos frecuente que "trozo", escogido por el traductor español (Ángel-Valente en Camus, 2001, p. 28) para la expresión francesa morceau de chocolat (Camus, 1942, p. 37). Los tres informantes españoles escogieron "trozo", mientras que 16 de los 24 informantes latinoamericanos escogieron de forma exclusiva "pedazo" y 8 aceptaron ambos sustantivos, señalando a veces "trozo" como más formal. El test realizado en CREA confirmó que se usa con mayor frecuencia "pedazo" en Colombia, Cuba, México, Perú y Venezuela, mientras que la proporción de "trozo" fue mayor en Chile y Argentina (Figura 3). Al final, podemos concluir que se trata de una costumbre americana de gran extensión.

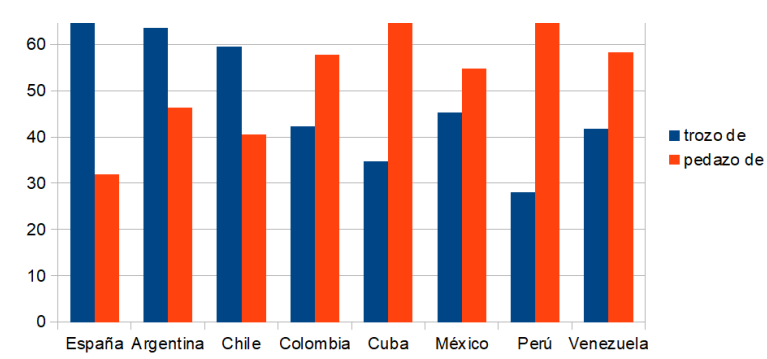

Figura 3 Extensión geográfica de las expresiones "trozo de"/ "pedazo de"

El verbo francés ajouter o el verbo equivalente augmenter en participio pasado es sistemáticamente traducido por Ángel-Valente por el verbo "añadir”, 
mientras que Pablo Montoya lo traduce por "agregar", tanto si el complemento de complemento de objeto se refiere a un objeto concreto, como a una palabra o frase (oral o escrita):

(5) [...] puis a tiré d'un gousset, augmentée du pourboire, la somme exacte qu'elle a placée devant elle. (Camus, 1942, p. 71)

[...] y retiró de un bolsillo, agregando la propina, la suma exacta que puso al frente de ella. (Montoya en Camus, 2013, p. 65)

[...] y sacó de un bolsito, con propina añadida, la suma exacta que colocó ante ella. (Ángel-Valente en Camus, 2001, p. 47)

(6) Mais cette fois, il n'a rien ajouté. (Camus, 1942, p. 136)

Pero esta vez no agregó nada. (Montoya en Camus, 2013, p. 116)

Pero esta vez, nada añadió. (Ángel-Valente en Camus, 2001, p. 92)

Aunque ambos verbos son comunes en España, el verbo "añadir" es mucho más frecuente en la lengua corriente, mientras que "agregar" pertenece a una lengua mucho más formal. De hecho, dos de los tres informantes españoles escogieron de manera exclusiva "añadir", mientras que el tercero aceptó los dos. En América Latina, en cambio, “agregar” es más frecuente que "añadir": de los 24 informantes latinoamericanos, 14 escogieron "agregar" de forma exclusiva, mientras que 10 aceptaron los dos; solo un informante escogió "añadir". Una búsqueda en CREA confirmó que salvo en Cuba, el verbo "agregar" se emplea mucho más que "añadir” en América Latina, al contrario de lo que ocurre en España (Figura 4).

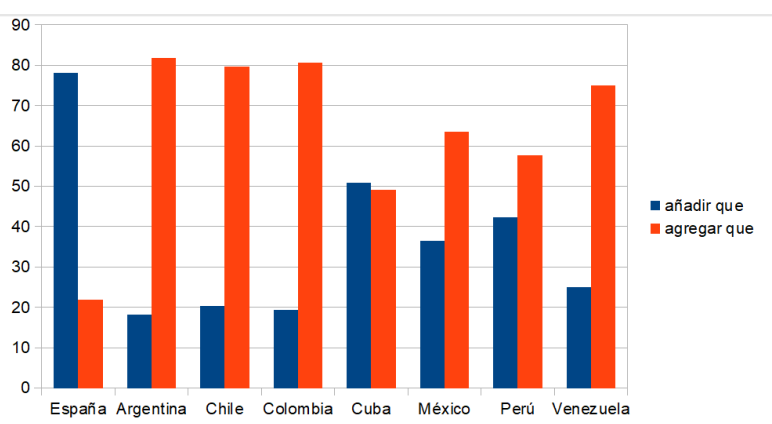

Figura 4 Extensión geográfica de las locuciones verbales "añadir que"/"agregar que"
La "morgue" de la traducción colombiana (Montoya en Camus, 2013, p. 23) es una palabra que existe en español peninsular, pero que resulta mucho menos frecuente que "depósito", término presente en la traducción española (Ángel-Valente en Camus, 2001, p. 11). Moreno de Alba (1992, p. 113) sugiere que "morgue" es la palabra mayoritariamente empleada en América Latina y señala "anfiteatro" como variante secundaria en México, Guatemala, Nicaragua y Colombia y "frigorífico” en Paraguay.

Para el término francés déjeuner (Camus, 1942, p. 35), sustantivo o verbo, el traductor español escogió varias veces "comer" (Ángel-Valente en Camus, 2001 , p. 16), mientras que el traductor colombiano optó por "almuerzo" /almorzar" (Montoya en Camus, 2013, p. 17). Según Haensch (2002, p. 63), la palabra "almuerzo" es mucho más frecuente en América Latina que en España: "la palabra corriente en España es comida. Almuerzo es más formal. Se usa para invitaciones oficiales y en hoteles y restaurantes (de cierta categoría)". De hecho, los tres informantes españoles optaron por “después de comer”, mientras que la mayoría de los latinoamericanos señalaron como usuales las dos expresiones.

$\mathrm{El}$ adjetivo "hermosa" empleado para calificar a una mujer aparece tanto en la traducción colombiana (Montoya en Camus, 2013, p. 69) como en la traducción española (Ángel-Valente en Camus, 2001, p. 46) como equivalente del francés belle. Sin embargo, el traductor colombiano emplea también el adjetivo "bella" (Montoya en Camus, 2013, p. 35), el cual, según Haensch (2001, p. 45), es mucho menos frecuente que "hermosa" y sobre todo que "guapa" en España, cuando se aplica a una persona. El test realizado en CREA confirma el empleo mucho menos frecuente de "bella" en España que en América Latina, donde coexiste, en mayor o menor proporción, con "hermosa”. Salvo en Perú, México, y, en menor medida, Argentina, "guapa" es muy poco empleado en América Latina (Figura 5). 


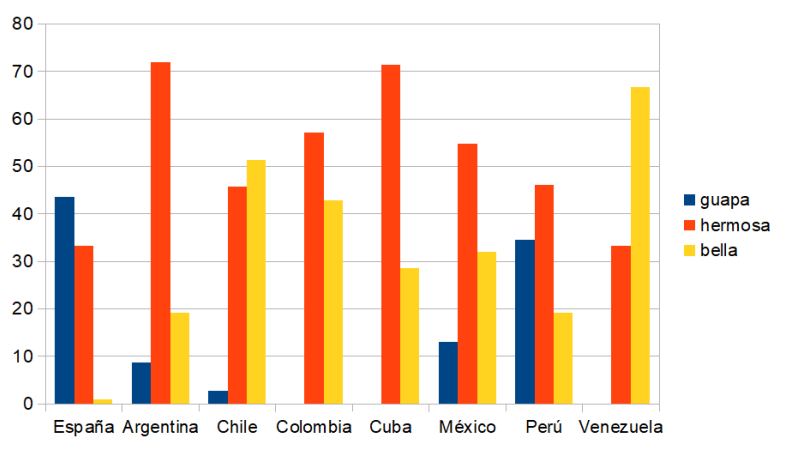

Figura 5 Extensión geográfica de los adjetivos "guapa"/ "hermosa"/ "bella"

El adjetivo "café" presente en la traducción colombiana ("una madre enorme, vestida de seda café", Montoya en Camus, 2013, p. 39) se usa, según el DicAm (Asociación de Academias de la lengua española, 2015, s. v. "café"), en muchos países latinoamericanos con la acepción de "de color café": en América Central (México, Guatemala, Honduras, El Salvador, Nicaragua, Costa Rica, Panamá, Cuba, República Dominicana) y también en Colombia, Ecuador, Perú, Bolivia, Chile, Paraguay, Argentina y Uruguay. Resulta difícil determinar si en estos países ese adjetivo es tan frecuente como "marrón", empleado en la traducción española (Ángel-Valente en Camus, 2001, p. 27) o más frecuente, pero, dada su extensión geográfica y su transparencia (metonimia: el objeto por su color), no plantearía ningún problema de comprensión ni generaría extrañeza en América Latina.

Según Molero, la voz "suburbio" presente en la traducción colombiana (Montoya en Camus, 2013, p. 41) se emplearía en Chile y Venezuela. De hecho, los cuatro informantes venezolanos, así como los cuatro chilenos y tres de los cuatro informantes colombianos rechazaron el término a favor de "afueras", vocablo empleado en la traducción española (Ángel-Valente en Camus, 2001, p. 28). Parece pues que Pablo Montoya escogió una voz de uso poco frecuente tanto en Colombia como en América Latina en general. En España, el término existe, pero se usa mucho menos que "extrarradio" o "afueras".

A partir del análisis, las Tablas 2 y 3 clasifican los términos presentes en la traducción colombiana y ausentes en la traducción española, según su grado de extensión en América Latina.

Desde el punto de vista de la comprensión, muy pocas palabras deberían plantear problemas a un lector latinoamericano no colombiano. Primero, porque los términos de baja extensión en América Latina son relativamente escasos (seis en total) en la traducción colombiana. Y segundo porque algunos de ellos, aunque no sean de uso común en muchos países latinoamericanos, son lo suficientemente transparentes como para no dificultar la comprensión. Solo "chanda", único colombianismo presente en la traducción de Montoya, "escaparate" y "emparedado" (aunque sea difícil sacar conclusiones claras para este término) podrían no ser entendidos. En cambio, las expresiones "vestido de baño" o "café negro", por su semejanza con las expresiones "traje de baño" o "café solo", y sobre todo por la transparencia de su composición, serán fácilmente entendidos. Del mismo modo, la proximidad del vocablo "suburbio” con el inglés suburb facilitará su comprensión. Lo único que pueden generar esos términos es un leve sentimiento de extrañeza en el lector.

Tabla 2 Términos de baja extensión en América Latina

\begin{tabular}{|c|c|c|}
\hline Colombianismos & $\begin{array}{l}\text { Americanismos de baja } \\
\text { extensión }\end{array}$ & $\begin{array}{c}\text { Americanismos de } \\
\text { extensión } \\
\text { dudosa (al parecer baja) }\end{array}$ \\
\hline Chanda & vestido de baño & suburbio \\
\hline \multirow[t]{2}{*}{ comer un pedazo (?) } & escaparate & emparedado \\
\hline & café negro & \\
\hline
\end{tabular}


Tabla 3 Términos de mediana o gran extensión en América Latina

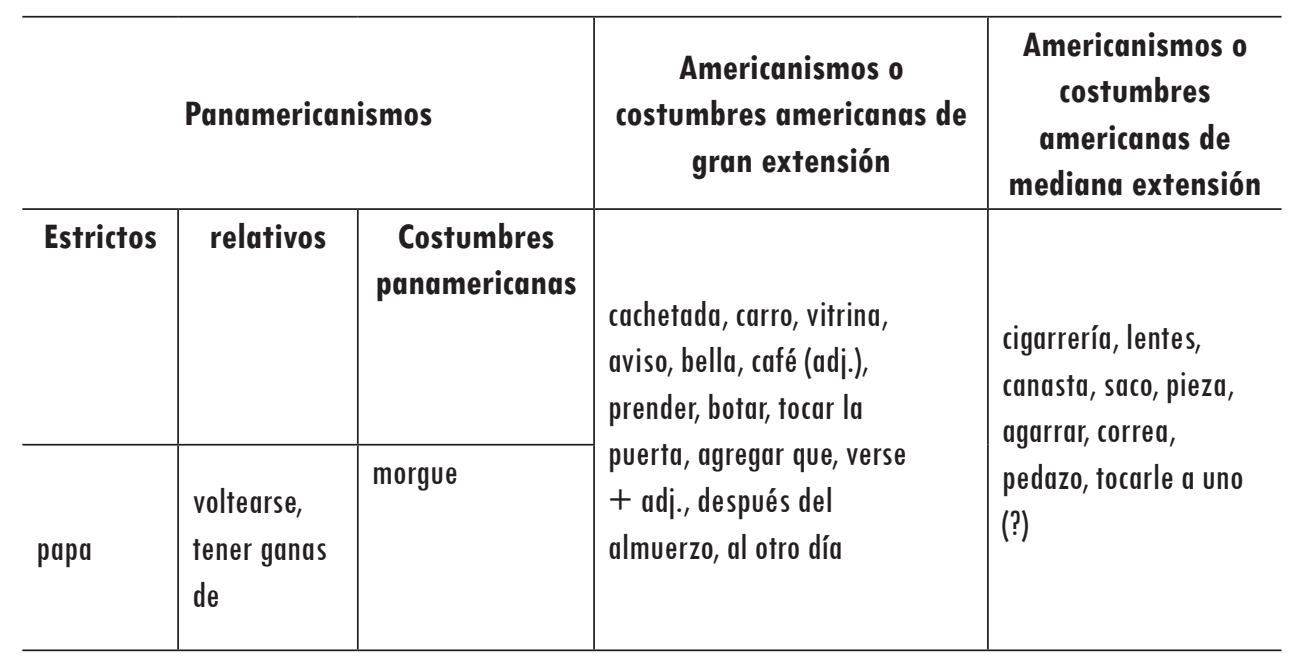

Solo encontramos cuatro panamericanismos en la traducción de Montoya, pero el resto de los americanismos son o de gran extensión o de extensión mediana en América Latina. Entre los americanismos de mediana extensión, solo "saco", "correa" tear problemas de comprensión a ciertos lectores latinoamericanos. En cambio, "lentes" y "cigarrería”, por su relativa transparencia, no deberían plantear ningún problema. En cuanto al vocablo "pieza", que para ciertos lectores latinoamericanos, no remite al "cuarto", sino a otras realidades muy distintas, el contexto siempre debería de ayudar a su comprensión. Por fin, las costumbres léxicas nunca plantearán problemas de comprensión precisamente porque son costumbre: la palabra más usada siempre coexiste con otra menos usada, pero ambas son entendidas en cualquier país latinoamericano, al igual que en España.

\section{Conclusiones}

De todo lo analizado, se puede afirmar que la traducción de Pablo Montoya, aunque destinada a un público colombiano, lleva pocas marcas diatópicas específicamente colombianas, tanto desde el punto de vista morfosintáctico como desde el punto de vista léxico, por lo que podría ser leída sin mayor molestia por una gran mayoría de lectores

latinoamericanos. La afirmación va más allá de meros problemas de comprensión. Recordemos lo que evocamos en la introducción: lo que experimentaron los lectores latinoamericanos respecto a las traducciones peninsulares que invadieron el continente americano a partir de los años sesenta no fueron problemas de comprensión, sino más bien un fuerte sentimiento de extrañeza que impedía que se apropiaran de la obra traducida, la cual, para ellos, siempre tenía un aire madrileño del que se sentían ajenos. La traducción de Pablo Montoya no debería defraudar a los lectores colombianos ni tampoco a una mayoría de lectores latinoamericanos: puede que algunos experimenten aquí y allá un leve sentimiento de extrañeza al tropezar con términos desconocidos o, caso más frecuente, con términos que no son los que ellos mismos usarían espontáneamente, pero pensamos que nunca la extrañeza será tal que pueda dificultar la lectura e impedir que el lector latinoamericano entienda la traducción. Como lo mencionamos más arriba, el vocabulario pasivo de un hablante latino-americano es en general mucho mayor de lo que se cree, debido a los viajes, a los intercambios universitarios y a los generados por los medios de comunicación y, en particular, por la telenovelas mexicanas y venezolanas; un término que no pertenece a su vocabulario activo no le parecerá tan exótico como si nunca lo hubiera oído. 
Además, el sentimiento de extrañeza que podría generar la traducción de Montoya no es de la misma índole que el que ha de generar en cualquier lector latinoamericano la traducción de Ángel-Valente en la que abundan términos privativos del español peninsular: "bañador", "patatas fritas", "la poli", "mono de trabajo" etc. Por motivos históricos relativos a la supremacía de la norma peninsular durante siglos, estos términos sólo muy recientemente han recibido el nombre de "hispanismo" o "españolismo": en la edición de 1992 del diccionario de la Real Academia Española, doce definiciones de lexemas llevan por primera vez la marca diatópica "Esp.", abreviación de "España", tal como lo indica la nomenclatura, pero el término de "españolismo" no figura en la nomenclatura ni tampoco tiene entrada en el diccionario. Hoy en día, el término ya tiene entrada "palabra o usos propios del español hablado en España” (Real Academia Española, 2014, s. v. "españolismo"), pero todavía no figura en la nomenclatura. Ahora bien, si los lectores latinoamericanos están acostumbrados a leer traducciones hechas en España, estos términos remiten inevitablemente a un espacio geográfico ajeno que también genera una extrañeza cultural que tiende a modificar el efecto producido por el texto fuente. Nada de eso en la traducción de Montoya, la cual es ante todo una traducción "americana": no una traducción a un hipotético y artificial español "neutro" entendible por cualquier lector latinoamericano, sino una traducción anclada en el espacio latinoamericano, tanto desde un punto de vista morfosintáctico como léxico.

Proponer una conclusión más global sobre la lengua usada hoy en día en las traducciones literarias en Colombia sería prematuro, ya que habría que realizar el mismo análisis a una escala mayor: primero examinar más traducciones destinadas a un público colombiano, y que pertenecieran a géneros distintos con el fin de apreciar también el papel de otro factor, el del registro lingüístico; luego examinar traducciones destinadas a un público latinoamericano, como las de la colección
Cara y Cruz. El análisis que se acaba de llevar a cabo pretende ser una primera etapa en la larga y difícil tarea de comprender cómo se traduce hoy en Colombia. Esperemos que el método desarrollado y los resultados conseguidos impulsen otros trabajos de la misma índole, tanto en el campo de la traducción literaria, como en el de la traducción no literaria.

\section{Referencias}

Academia Mexicana de la Lengua (2016). Diccionario de mexicanismos [Edición digital]. Siglo XXI. https:// www.academia.org.mx/obras/obras-de-consultaen-linea/diccionario-de-mexicanismos

Asociación de Academias de la Lengua Española (2015). Diccionario de americanismos. Penguin Random House.

Assouline, P. (2009). Divorcer du castillan. Le Monde. https://www.lemonde.fr/livres/article/2009/03/12/ divorcerducastillan_1166896_3260.html

Bastin, G. (2003). Por una historia de la traducción en Hispanoamérica. Íkala, Revista de Lenguaje y Cultura, 8(14), 193-217.

Borges, J. L. (2001 [1977]). Un bárbaro en Asia. Tusquets.

Camus, A. (1942). L'étranger. Gallimard.

Camus, A. (2001). El extranjero (Traducción de José ÁngelValente). Alianza.

Camus, A. (2013). El extranjero (Traducción de Pablo Montoya). (Colección Palabras rodantes). Comfama, Metro de Medellín.

Díaz-Oyarzábal, I. (2017). El español neutro en la traducción literaria - Análisis de dos versiones de The third man. (Trabajo fin de grado). Universidad Pontificia Comillas, Madrid. https://repositorio.comillas.edu/jspui/ bitstream/11531/21671/1/TFG001531.pdf

Fontanella de Weinberg, M. B. (1992). Una variedad lingüística en busca de su propia identidad: el español bonaerense a lo largo del siglo Xx. En M. B. Fontanella de Weinberg, P. Vallejos de Llobet, e Y. Hipperdinger (Eds.), Estudios sobre el español de la Argentina (pp. 63-76). I. Departamento de Humanidades, Universidad Nacional del Sur.

Gómez-Pablos, B. (1999). Dos versiones al español de una obra italiana. Observaciones sobre las variantes diatópicas en la traducción. Hieronymus Complutensis, 8, 135-144. http://cvc.cervantes.es/lengua/ hieronymus/pdf/08/08_135.pdf 
Gómez-Pablos, B. (2001). Las traducciones de América de Franz Kafka a ambos lados del océano. Tercer Congreso Latinoamericano de Traducción e Interpretación. De Babel a Internet. 23 al 25 de abril de 2001. (Tomo II). Colegio de Traductores Públicos de la Ciudad de Buenos Aires, Argentina.

Haensch, G. (2001). Español de América y español de Europa (Primera parte).Panace@, 2(6), 63-72. https://www. freewebs.com/lenguaje2007/n6_G_Haensch.pdf

Haensch, G. (2002). Español de América y español de Europa (Segunda parte).Panace@, 3(7),37-64. http:// www.tremedica.org/panacea/IndiceGeneral/ n7_G_Haensch7.pdf

Haensch, G, y Werner, R. (1993a). Nuevo diccionario de colombianismos. Instituto Caro y Cuervo.

Haensch, G, y Werner, R. (1993b). Nuevo diccionario de uruguayismos. Instituto Caro y Cuervo.

Haensch, G, y Werner, R. (2002). Diccionario del español de Argentina: español de Argentina-español de España. Instituto Caro y Cuervo.

Haensch, G, y Werner, R. (2003). Diccionario del español de Cuba: español de Cuba-español de España. Instituto Caro y Cuervo.

Kany, C. (1976). Sintaxis hispanoamericana. Gredos.

Lipski, J. (1996). El español de América. Cátedra.

Lope Blanch, J. M. (1977). El concepto de prestigio y la norma lingüística del español. En Estudios de lingüistica española (pp. 29-46). Universidad Nacional Autónoma de México. https://revistas-filologicas.unam.mx/ anuario-letras/index.php/al/article/view/267/266

Michaux, H. (2001). Un bárbaro en Asia (Traducción de Jorge Luis Borges). Tusquets Editores.

Molero Pintado, A. (2003). El español de España y el español de América: vocabulario comparado. Ediciones SM.

Moliner, M. (2004). Diccionario de uso del español. Gredos.

Moreno de Alba, J. (1992). Diferencias léxicas entre Españay América. Mapfre, S. A.

Moreno de Alba, J. (1996). Léxico de las capitales americanas frente al léxico madrileño. Lexis, $X X(1-2)$, 487-501. http://revistas.pucp.edu.pe/index.php/lexis/article/ view $/ 7474 / \mathrm{pdf}$

Navarro Arisa, J.J. (1999). "Rimbaud ha tenido más éxito que Marx”: Pere Gimferrer. El Cultural, https://elcultural.com/Rimbaud-ha-tenido-mas-exito-que-Marx

Orozco, W. (2000). La traducción en el siglo XIX en Colombia. Íkala, Revista de Lenguaje y Cultura, 5(9-10), 73-88.

Pulido, M., Tipiani, M. V. (2012). La práctica de la traducción literaria en Colombia desde la década de los noventa hasta hoy. En G. Adamo (Ed.), La traducción literaria en América Latina (pp. 67-81). Paidós.

Real Academia Española (2014). Diccionario de la lengua española. https://www.rae.es

Restrepo, E. (2017). Palabras rodantes. El Colombiano. http:// www.elcolombiano.com/opinion/columnistas/ palabras-rodantes-GJ6830811

Sánchez-Méndez, J. (2003). Historia de la lengua española en América. Tirant Lo Blanch.

Sundell, D. (2010). El español neutro en la traducción intralingüistica. Un estudio sobre el uso del español neutro en las traducciones intralingüisticas de Harry Potter y la Orden del Fénix. [Tesis de maestría en lengua española]. Oslo, Noruega: Universidad de Oslo, Facultad de Humanidades. https://www.academia. edu/28068648/El_español_neutro_en_la_traducción_intralingü\%C3\%ADstica

Tipiani, M. V. (2013). El proceso editorial de la traducción en Colombia: entrevista a Iván Hernández Arbeláez, editor de Cara y Cruz, Editorial Norma. Mutatis Mutandis. Revista Latinoamericana de Traducción, 6(2), 567-572.

Vaquero de Ramírez, M. (1998). El español de América II: Morfosintaxis y Léxico. Arco/Libros, S. L.

Vega (de la), M. C. (2018). Traducciones de El mago de Oz en español neutro del Cono Sur. Nueva Recit: Revista del Área de Traductología, 1. https://revistas.unc.edu.ar/ index.php/ReCIT/article/view/20144

Yourcenar, M. (2011 [1982]). Memorias de Adriano. (Traducción de Julio Cortázar). Edhasa.

Cómo citar este artículo: Weber, Élodie (2020). La traducción de El extranjero de Albert Camus por Pablo Montoya: ¿una traducción para lectores latinoamericanos? Íkala, Revista de Lenguaje y Cultura, 25(2), 513-532. https://doi.org/10.17533/udea.ikala.v25n02a12 